\title{
UNIQUE MULTIPLE SEX CHROMOSOMES OF THE TREE MOUSE VANDELEURIA O. OLERACEA: IDENTIFICATION OF $\mathrm{X}_{1}$ AND $\mathrm{X}_{2}$
}

\author{
RAJIVA RAMAN and T. SHARMA \\ Cytogenetics Laboratory, Department of Zoology, Banaras Hindu University, Varanasi-221005 India
}

Received 8.vi.76

\begin{abstract}
SuMMARY
The tree mouse Vandeleuria o. oleracea has an odd diploid chromosome complement $\left(2 n=29 \% / \delta^{*}\right)$ accompanied by a unique multiple sex-chromosome mechanism $\left(\mathrm{X}_{1} \mathrm{X}_{2} \mathrm{Y}_{\delta} / \mathrm{X}_{1} \mathrm{X}_{1} \mathrm{X}_{2}\right.$ ) $)$. In the present paper the sex chromosomes have been identified unequivocally with the help of G-banding and DNA replication patterns which confirm our earlier suggestion that the $\mathrm{X}_{1}$ is smaller in size than the simple mammalian $\mathrm{X}$, and also that the combined sizes of the $\mathrm{X}_{1}$ and $\mathrm{X}_{2}$ (3.8 and 1.7 per cent respectively) approximate to the size of the conservative mammalian $\mathrm{X}$ ( 5 per cent). It is proposed that the mammalian $\mathrm{X}$ has attained a minimum functional size so that further reduction is not tolerated.
\end{abstract}

\section{InTRODUCTION}

Sharma AND Raman (1972) observed a novel multiple sex-chromosome system $\left(\mathrm{X}_{1} \mathrm{X}_{1} \mathrm{X}_{2}\right.$ of $\left./ \mathrm{X}_{1} \mathrm{X}_{2} \mathrm{Y}_{\circlearrowleft}\right)$ in the somatic and meiotic cells of males and somatic cells of females of a rodent Vandeleuria o. oleracea, in which the presumptive $\mathrm{X}_{1}$ was distinctly smaller than the simple mammalian $\mathrm{X}$. This observation was in clear contrast to the overwhelming data available regarding the constancy in the size of the mammalian $\mathrm{X}$ chromosome (Ohno, 1967). The apparent reduction in the size of the $\mathrm{X}$ in Vandeleuria seemed to call into question the validity of the suggestion of the conservatism of the $\mathrm{X}$ chromosome in mammalian evolution. This discrepancy was explained on the basis of our observation that the combined size of the single presumptive $\mathrm{X}_{1}$ and the $\mathrm{X}_{2}$ formed a little more than 5 per cent of the genome, the size of the conservative $X$. We tentatively suggested that the multiple $\mathrm{X}$ chromosomes in Vandeleuria o. oleracea arose by the fragmentation of the original $\mathrm{X}$. However, because of the limitation of the techniques then employed, an unambiguous recognition of the $\mathrm{X}_{1}$ and $\mathrm{X}_{2}$ was essential to substantiate the above proposal.

In the present paper we report the G-band and DNA replication patterns of the sex chromosomes of Vandeleuria o. oleracea to enable their unequivocal identification. We confirm our previous suggestion that the $\mathrm{X}_{1}$ is distinctly smaller than the mammalian $\mathrm{X}$, and that the combined size of the single $\mathrm{X}_{1}$ and $\mathrm{X}_{2}$ make approximately 5 per cent of the genome. On the basis of (1) the reduction in the size of the $\mathrm{X}_{1}$, (2) the equivalence of the combined sizes of the $\mathrm{X}_{1}$ and $\mathrm{X}_{2}$ with the size of the original $\mathrm{X}$ chromosome and (3) the retention of the $X_{2}$ in both the sexes, even as an odd element, it seems that 5 per cent of the mammalian genome is the minimum required for $\mathrm{X}$ chromosome function. 


\section{Materials AND Methods}

Despite regular attempts to procure more specimens of $V$. o. oleracea following our first report on its chromosomes, only two more individuals (both males) could be obtained from a sugar cane field in Varanasi. Chromosome preparations were made from bone marrow, spleen, lung (in vitro) and testis (in vivo). Bone marrow was incubated in the culture media for 5 hours. The techniques for culturing spleen, and the preparation of slides and autoradiography were the same as routinely performed in this laboratory (Sharma and Raman, 1973). From one individual a monolayer culture of lung cells was grown in a T-flask. Small lung pieces were grafted on coverglasses, placed in the tube and grown on McCoy's 5A media supplemented with 20 per cent human $A B$ serum. The cells were grown for 21 days and then harvested after trypsinisation. G-bands were induced by treating slides with 0.025 per cent trypsin (Difco) dissolved either in $\mathrm{Ca}^{++}$, $\mathrm{Mg}^{++}$-free Hanks' medium or in distilled water $(p \mathrm{H} \mathrm{7.6)}$. The quality of the bands was equally good in both the cases, however, the water-dissolved trypsin remained uninfected for a much longer period. Chromosomes were photographed with a Carl-Zeiss photomicroscope. Karyotypes were made from G-band metaphases only.

\section{Observations}

Fifty metaphases from each individual were analysed to determine the diploid number, which was 29 in all the tissues including the lungs. The latter was utilised to check the constitution of cells of endodermal origin.

\section{(i) G-bands}

The banding pattern of each pair of chromosomes was characteristic (fig. 1) and was comparable in both the individuals. However, the bands in the smaller chromosomes were not very distinct even in moderately contracted plates. In total 10 photographed cells were karyotyped, 7 from one individual and 3 from the other.

The main objective of the present study was to distinguish the sex chromosomes unequivocally, i.e. to recognise those chromosomes which were unpairable. The banding pattern revealed three small-sized acrocentrics which could not be paired either within themselves or with any chromosome of the complement (fig. 2). Of these three, two chromosomes could be identified as the smallest chromosomes of the complement even in the untreated cells, but the third chromosome could not be distinguished from the other acrocentrics. The latter, which was the biggest of the three, possessed two distinct dark bands, one nearly in the middle and the other in the distal region of the chromosome. Although the banding pattern of this chromosome did resemble that of the chromosome number 11 , the presence of a minute but distinct short arm and a prominent G-band negative region on the telomeric end of the long arm in chromosome 11 , coupled with the difference in size, clearly distinguished the two chromosomes. Thus, the biggest unpairable chromosome was $\mathrm{X}_{1}$, which comprised 3.8 per cent \pm 0.09 of the genome. Of the other two unpairable chromosomes, the bigger was completely dark with a slightly darker band at the distal end. The size of this chromosome 

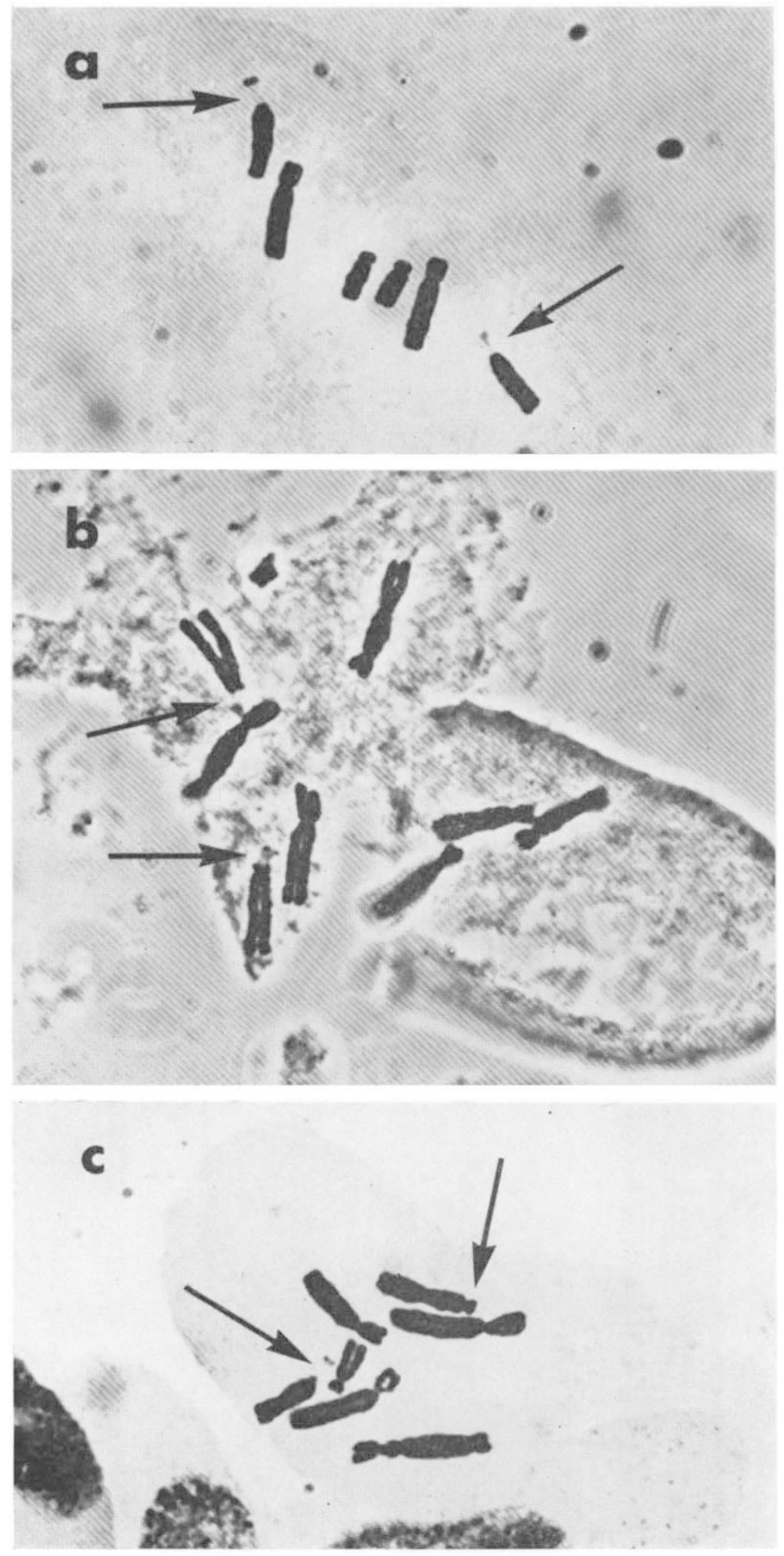

Plate I

Photomicrographs of the chromosomes of $(a)$ Crepis capillaris $(2 n=6),(b)$ Crepis dioscorides $(2 n=8)$, and $(c)$ Crepis capillaris $\times$ Crepis dioscorides (chromosome number $=7)$. The arrows point to the satellite region of the SAT chromosomes. Note the absence of a satellite in one of the two SAT chromosomes in the hybrid (c). Magnification ca. 1500. 
Fig. 1-G-band karyotype of V. o. oleracea male. $\times 2000$.

Frg. 2.-Partial G-band karyotype of acrocentric chromosomes from three plates of $V$. 0 . oleracea male. The first pair of each set from fig. $1 . \times 2000$.

Frg. 3a.-Autoradiograph of a metaphase from male $V$. o. oleracea. Arrow indicates the " hot" Y chromosome. $\times 1600$.

Fig. 3b.-The same plate after removing the grains. Single arrow indicates the $Y$. Double arrow points out the $\mathrm{X}_{2} . \times 1600$. 
was 2.6 per cent. The smallest chromosome (relative length 1.7 per cent \pm 0.09 ), the short arm of which was not always discernible, was almost unstained except for a very thin band at the centromeric region.

\section{(ii) Autoradiography}

Pattern of late-S DNA replication was studied in spleen as well as bone marrow cells (in vitro). The cells were given a continuous treatment of ${ }^{3} \mathrm{H}-\mathrm{TdR}$ (BARG, India; specific activity $6.0 \mathrm{Ci} / \mathrm{mm} ; 1 \mu \mathrm{Ci} / \mathrm{ml}$ culture suspension) for 6 hours and 4 hours in spleen, and 5 hours and $3 \frac{1}{2}$ hours in bone marrow, prior to fixing the cells. Fifty cells from spleen and 30 cells from bone-marrow were observed. The labelling pattern was completely consistent. In almost all the cells one chromosome was distinctly more heavily labelled during the late-S (fig. 3). After removing the grains it was seen to be the second smallest chromosome of the karyotype. The heterochromatic nature of this chromosome confirmed it as the $\mathrm{Y}$ chromosome.

\section{(iii) Meiosis}

Meiosis in Vandeleuria o. oleracea has already been documented in detail (Sharma and Raman, 1972). It was reported that the odd element was. consistently included within the sex vesicle which unravelled into a sex heterotrivalent displaying an end-to-end association during the advanced stages of meiosis-I. In meiosis-II, equal numbers of daughter cells were found to be endowed with either the $\mathrm{X}_{1}$, or the $\mathrm{X}_{2}$ and $\mathrm{Y}$ chromosomes. In the two individuals studied, the behaviour of the sex chromosomes during meiosis was identical to that observed in the earlier work. The sex heterotrivalent was present in all the 100 metaphase-I plates examined. No univalent was observed in any plate.

Thus, based on these studies of meiosis, G-band pattern and pattern of DNA replication, the odd element was confirmed as a sex chromosome and the $\mathrm{X}_{1}, \mathrm{X}_{2}$ and $\mathrm{Y}$ were unequivocally identified. They constituted 3.8 per cent $\pm 0.09,1.7$ per cent \pm 0.09 and 2.6 per cent of the genome respectively.

\section{Discussion}

Following the report on the odd diploid number $(2 n=29)$ (Pathak, 1971 ; Sharma and Raman, 1972) and the multiple sex-chromosome system $\left(\mathrm{X}_{1} \mathrm{X}_{1} \mathrm{X}_{2}+\mathrm{X}_{1} \mathrm{X}_{2} \mathrm{Y}_{0}\right.$ ) in $V$. o. oleracea (Sharma and Raman, loc. cit.) several papers describing different chromosome numbers for different subspecies of Vandeleuria $(2 n=26,28,30)$ have been published (Gropp et al., 1972; Satyaprakash and Aswathanarayan, 1973; Sharma et al., 1975; Rao and Jhanwar, personal communication). The sex-chromosome system, in all these cases, was the $\mathrm{XX}$ \% $/ \mathrm{XY} \delta$ type. However, the present paper indicates that at least the Varanasi population of $V$. o. oleracea consistently possesses the odd diploid number and that the odd element is an integral part of the sex chromosome complex. In addition, this report identifies the sex chromosome unequivocally.

The presence of a smaller $\mathrm{X}_{1}$ and the unpaired $\mathrm{X}_{2}$ in Vandeleuria o. oleracea has certain important implications with regard to the conservatism of the mammalian $\mathrm{X}$. The $\mathrm{X}$ chromosome in mammals appears as one of the most 
constant elements of eutherian evolution (Ohno, 1969). In a large majority of the species it contributes 5 per cent to the genome (Atkin et al., 1965). It is also notable for the dosage compensation mechanism whereby only one of the $\mathrm{X}$ remains genetically active in the female. Nevertheless, there are certain exceptions to the standard size of the $\mathrm{X}$ chromosome; on one hand the $\mathrm{X}$ is increased in size by $\mathrm{X}$-autosome translocation or by the addition of constitutive heterochromatin, and on the other hand one of the two Xs in females is partially deleted or completely dispensed with from somatic and/or germ cells (for detailed account see Ohno, 1969; Fredga, 1970; Sharma and Raman, 1972). In Akodon azarae (Bianchi and Contreras, 1967) and Mus minutoides musculoides (Matthey, 1967), several normal females with one normal and one deleted $\mathrm{X}$ chromosome ( $\mathrm{Xx}$ ) ) have been obtained from natural populations. Clearly the effect of these reductions in the size of the $\mathrm{X}$ chromosome is circumvented by the dosage compensation mechanism, notwithstanding the fact that the genetic influence of the facultative $\mathrm{X}$ may vary in man and rodents (Sharma and Raman, 1971). It is noteworthy, however, that neither in Akodon nor in Mus has a single female homozygous for the deleted x chromosomes $(\mathrm{xx})$ or a male with deleted $\mathrm{x}$ and $\mathrm{Y}$ been discovered. Apparently further reduction in the $\mathrm{X}$ component is not viable. In this context, $V$. o. oleracea appears to be the solitary case where the $\mathrm{X}_{1}$ is considerably smaller ( 3.8 per cent) than the standard mammalian $\mathrm{X}$. However, the combined value of the $\mathrm{X}_{1}$ and $\mathrm{X}_{2}(1.7$ per cent) forms the characteristic size of the mammalian X. It is likely, therefore, that in $V$. o. oleracea also, the content of the normally conservative $\mathrm{X}$ has not been reduced in relation to the size of the genome; instead the chromosome has just broken into two parts.

The constancy of the size of the $\mathrm{X}$, throughout eutherian mammals, may also indicate a similarity in its gene content in various mammalian species. This is also suggested by the presence of several identical X-linked loci in different species (Ohno, 1969). Thus on the basis of the conservatism in the size and retention of $\mathrm{X}_{1}$ and $\mathrm{X}_{2}$ in Vandeleuria, it seems plausible to suggest that during mammalian evolution the size of the $\mathrm{X}$ has attained a minimum threshold level. Perhaps it is for this reason that the deleted $\mathrm{xx}$ and deleted $\mathrm{xY}$ as well as OO and OY (Morris, 1968) individuals are not encountered and perhaps it is for the same reason that the $\mathrm{X}_{2}$ is retained in Vandeleuria even as an odd element.

However, the mechanism of fragmentation of the original $\mathrm{X}$ into $\mathrm{X}_{1}$ and $\mathrm{X}_{2}$, the pairing sites between $\mathrm{X}_{1}$ and $\mathrm{X}_{2}$ during meiosis and the precise functional role of $\mathrm{X}_{2}$ are not at all clear.

Acknowledgments.-The authors are grateful to the University Grants Commission, India, for financial assistance.

\section{References}

ATKin, N. B., MATtinson, G., BECAK, w., AND ohno, s. 1965. The comparative DNA content of 19 species of placental mammals, reptiles and birds. Chromosoma, 17, 1-10.

BIANCHI, N. O., AND CONTRERAs, J. R. 1967. The chromosomes of the field mouse Akodon azarae (Cricetidae, Rodentia) with special reference to sex chromosome anomalies. Cytogenetics, 6, 306-313.

FREDGA, K. 1970. Unusual sex chromosome inheritance in mammals. Philos. Trans. roy. Soc. $B, 259,15-36$. 
GROPP, A., MARKWONG, A., MARShALL, J., AND kIM, Y. J. 1972. Robertsonian chromosomal variation in the long tailed tree mouse (Vandeleuria). Z. Zool. Systemat. Evolutionforsch, 10, 210-214.

MAtThey, R. 1967. Étude de deux femelles hétérozygotes pour une délétion partielle portant sur un bras du chromosome $\mathbf{X}$ chez Mus (Leggada) minutoides musculoides Temm. Cytogenetics, 6, 168-177.

MORRIs, T. 1968. The XO and OY chromosome constitution in the mouse. Genet. Res., Camb., 12, 125-137.

oнno, s. 1967. Sex Chromosomes and Sex-linked Genes. Springer-Verlag, Berlin/Heidelberg/ New York.

OHNo, s. 1969. Evolution of sex chromosomes in mammals. Ann. Rev. Genet., 3, 495-524. pathak, s. 1971. Chromosomes of the long tailed climbing mouse Vandeleuria oleracea (Bennett) (Muridae-Rodentia). Mamm. Chrom. Nerosl., 12, 60.

SATYAPRAKASH, K. L., AND ASWATHANARAYAN, N. v. 1973. Diversity of the karyotype in the Indian long-tailed tree mouse Vandeleuria oleracea (Bennett). Curr. Sci., 42, 755-756.

SHARMA, T., AND RAMAN, R. 1971. An XO female in the Indian mole rat. F. Heredity, 62, 384-387.

SHARMA, T., AND RAMAN, R. 1972. Odd diploid number in both sexes and a unique multiple sex-chromosome system of a rodent, Vandeleuria o. oleracea (Bennett). Cytogenetics, 11, 247-258.

SHARMA, T., AND RAMAN, R. 1973. Variation of constitutive heterochromatin in the sex chromosomes of the rodent Bandicota bengalensis bengalensis (Gray). Chromosoma. Berl., 41, 75-84.

SHARMA, T., RAMAN, R., GARG, G. s., Gadi, I. K., AND GuPta, P. 1975. C-band and Bibenzimidazol (33258 Hoechst) fluorescence in chromosomes. Abstract. V Cell Biology Conf. pp. 2-3, Delhi University. 